\title{
Itinerários líricos por Ouro Preto em revistas do Estado Novo português e brasileiro: Mário de Andrade, Carlos Drummond de Andrade, Henriqueta Lisboa e Cecília Meireles
}

\author{
Lyrical itineraries through Ouro Preto in portuguese \\ and brazilian Estado Novo magazines: Mário de \\ Andrade, Carlos Drummond de Andrade, \\ Henriqueta Lisboa and Cecília Meireles
}

Luís Antônio Contatori Romano Unifesspa/CNPq

\section{DoI}

https://doi.org/10.37508/rcl.2021.n46a449

\section{RESUMO}

Este artigo visa discutir quatro textos sobre Ouro Preto de escritores brasileiros, publicados em revistas do Estado Novo português e brasileiro. São eles: um ensaio de Mário de Andrade sobre o Aleijadinho, poemas de Carlos Drummond de Andrade e Henriqueta Lisboa, todos publicados na Atlântico: Revista Luso-Brasileira, e uma crônica de Cecília Meireles, "Holy-week in Ouro Preto", publicada na revista Travel in Brazil. Objetiva-se analisar como esses textos se relacionam com políticas de bens históricos e artísticos nacionais e com a difusão do turismo em Ouro Preto na década de 1940, compondo itinerários turístico-literários por essa cidade.

Palavras-Chave: revista Atlântico, revista Travel in Brazil, itinerários literários, literatura e turismo. 


\section{Abstract}

This article aims to discuss four texts about Ouro Preto by Brazilian writers, published in Portuguese and Brazilian Estado Novo magazines. They are: an essay by Mário de Andrade about Aleijadinho, poems by Carlos Drummond de Andrade and Henriqueta Lisboa, all published in Atlântico: Revista Luso-Brasileira, and a chronicle by Cecília Meireles, "Holy-week in Ouro Preto", published in Travel in Brazil magazine. The aim is to analyze how these texts relate to policies of national historic and artistic assets and to the diffusion of tourism in Ouro Preto in the 1940s, composing tourist-literary itineraries through this city.

KEYWORDS: Atlântico magazine, Travel in Brazil magazine, literary itineraries, literature and tourism.

\section{Introdução}

Focalizar-se-á, neste artigo, um conjunto de quatro textos sobre Ouro Preto, de renomados escritores brasileiros, publicados, na década de 1940, na Atlântico - revista luso-brasileira e na revista Travel in Brazil. Objetiva-se discutir como esses textos se inserem nas políticas do Estado Novo brasileiro direcionadas à preservação de bens históricos e artísticos nacionais e à difusão do turismo e em que medida eles podem compor itinerários turístico-literários por Ouro Preto.

A Atlântico era uma revista literária binacional, sem propósitos explicitamente turísticos, que resultou do Acordo Cultural Luso-Brasileiro, firmado em 1941. Em seu número inaugural, de 1942, foram publicados o poema "O vôo sobre as igrejas", de Carlos Drummond de Andrade, e o ensaio “O gênio e a obra de Aleijadinho”, de Mário de Andrade. Em 1946, saiu "Poesia de Ouro Preto", de Henriqueta Lisboa.

A Travel in Brazil era uma publicação, em inglês, da Divisão de Turismo do DIP, sob editoria de Cecília Meireles. Essa revista tinha como propósito explícito divulgar, principalmente nos Estados Unidos, realizações da ditadura de Getúlio Vargas, para isso instrumen- 
talizava a difusão do turismo no Brasil. Além de colaboradores oficiais do regime e de colunas destinadas à propaganda de Vargas, essa revista publicou textos de escritores envolvidos com a problemática da identidade nacional, tais como Mário de Andrade, Manuel Bandeira, Sérgio Buarque de Holanda, além da própria Cecília Meireles, entre outros. No último número da Travel in Brazil, de 1942, Cecília Meireles publica um longo e minucioso relato intitulado "Semana Santa em Ouro Preto".

O artigo de Mário de Andrade centra-se no estilo artístico e na personalidade de Aleijadinho e tem caráter ensaístico. As fontes com as quais Andrade dialoga sobre o estilo do artista são viajantes estrangeiros, principalmente Francis Richard Burton, que esteve em Minas Gerais em 1867. Sobre a personalidade de Aleijadinho, Andrade dialoga com a obra Traços biográficos, escrita por Rodrigo José Ferreira Bretas em 1858, 44 anos após a morte do artista. Esse livro teve uma edição posterior em 1951, do IPHAN, com a inserção de um conjunto de notas explicativas.

Os poemas de Carlos Drummond de Andrade e de Henriqueta Lisboa tematizam passeios por Ouro Preto, que podem ser lidos como itinerários literários pela cidade. No poema de Drummond, o leitor acompanha com o eu-lírico uma procissão de Semana Santa até a Matriz de Antônio Dias, onde está a campa de Aleijadinho. A voz coral dos anjos louva a memória do artista. No poema de Henriqueta Lisboa, o leitor acompanha o eu-lírico a percorrer ruas de Ouro Preto, a partir do casarão onde viveu a musa do poeta Gonzaga, transfigurada na Marília de Dirceu. Ao passar por monumentos, tece referências à história da cidade, desde o início do século XVIII. Na Igreja de Nossa Senhora das Mercês e dos Perdões, entrega-se à contemplação artística.

Cecília Meireles compõe um minucioso relato de sete dias, desde o Domingo de Ramos até o Domingo de Páscoa. Aos eventos religiosos soma elementos paisagísticos, locais de hospedagem, entreteni- 
mentos, descrições de detalhes arquitetônicos das igrejas e acontecimentos históricos, a fim de atrair o leitor, para que este se converta seja num turista religioso, seja num viajante curioso por conhecer uma cultura estrangeira.

Esses textos serão situados, primeiramente, no contexto das políticas culturais do Estado Novo português e do brasileiro voltadas para a construção de identidades nacionais e a instrumentalização do turismo como forma de divulgação de realizações governamentais. Em seguida, serão apresentados conceitos relativos à Literatura de Viagens e à Literatura de Turismo, a partir dos quais os textos serão focalizados como referências para possíveis itinerários turísticos literários por Ouro Preto.

\section{O Acordo Cultural Luso-Brasileiro e a Criação}

\section{da Revista Atlântico}

No início dos anos de 1940, Brasil e Portugal viviam sob regimes ditatoriais, denominados de Estado Novo: a ditadura de Getúlio Vargas (1937-1945) e a de Oliveira Salazar (1933-1974). Os dois regimes tinham órgãos similares de propaganda. No Brasil, o Departamento de Imprensa e Propaganda (DIP), existiu entre 1939 e maio de 1945 , quando foi substituído pelo Departamento Nacional de Informação (DNI), dissolvido em 1946. Em Portugal, Salazar criou o Secretariado da Propaganda Nacional (SPN) em 1933, que, em 1945, passou a chamar Secretariado Nacional de Informação, Cultura Popular e Turismo (SNI). No Brasil, o DIP foi dirigido por Lourival Fontes de 1939 a 1942, sendo sucedido por Coelho dos Reis entre 1942 e 1943 e por Amílcar Dutra de Menezes, de 1943 até sua extinção em 1945. Em Portugal, António Ferro foi o gestor do SPN desde sua criação em 1933 até 1950, quando já havia se tornado DNI.

Entre as funções do DIP e do SPN estava a promoção do turismo e das artes nacionais. Com esse objetivo, em 1941, lançaram as re- 
vistas ilustradas Travel in Brazil e Panorama: revista portuguesa de arte e turismo. A revista brasileira destinava-se ao potencial turista estadunidense, enquanto a revista portuguesa visava desenvolver o turismo interno. Ambas estiveram sob responsabilidade de personalidades da vida intelectual de cada país: Cecília Meireles foi editora da Travel in Brazil, entre 1941 e 1942, e o jornalista António Ferro foi o mentor da Panorama, entre 1941 e 1949.

António Ferro e sua esposa, a poeta Fernanda de Castro, estiveram no Brasil pela primeira vez em 1922. Em abril de 1923, o casal retornou a Portugal, mas sua conferência "A idade do jazz-band" mereceu uma carta aberta elogiosa de Oswald de Andrade, publicada na revista portuguesa Contemporânea, em março de 1925 (RIBEIRO, 2017a). Ferro era uma figura ambígua, seu modernismo associava-se a um nacionalismo de inspiração fascista, o que o levou a realizar três entrevistas com Mussolini, nos anos de 1923, 1926 e 1934, por quem nutria admiração. Em 1932, entrevistou Oliveira Salazar, que, em 1933, já à frente do governo português, convida-o para dirigir o SPN.

No SPN, Ferro idealiza a "Política do Espírito", que visava promover a renovação do nacionalismo entre os portugueses, a partir de valores rurais e da cultura popular, ao mesmo tempo em que esses elementos culturais deveriam passar por um processo de estetização ao gosto das classes urbanas privilegiadas. Para isso, o SPN criou a Campanha do Bom Gosto, de que a revista Panorama foi divulgadora, e mobilizou um leque de atividades culturais: as artes plásticas, a imprensa, o teatro, a literatura, a radiodifusão, o cinema, assim como um grupo de artistas e escritores renomados dispostos a fornecer seus serviços remunerados para o Estado Novo português (RIBEIRO, 2017b).

Em 1941, como diretor do SPN, António Ferro retorna ao Brasil e assina, conjuntamente com Lourival Fontes, diretor do DIP, o Acordo Cultural Luso-Brasileiro, que deu origem à revista Atlântico, destinada à divulgação da literatura de ambos os países, editada entre 
1942 e 1950. No primeiro número da Atlântico, constam a primavera de 1942, como data de publicação, e os nomes de Ferro e Fontes como seus diretores. Na Atlântico colaboraram escritores ligados a tendências modernistas do Brasil e de Portugal.

O primeiro número da Atlântico se abre com o editorial "Algumas Palavras”, em que António Ferro apresenta os propósitos do Acordo Cultural Luso-Brasileiro:

Qual o nosso objetivo? Qual o nosso programa? Revelar Portugal novo aos brasileiros. Revelar o novo Brasil aos portugueses. (...) O que o Brasil deseja conhecer de Portugal não é apenas o seu passado mas o seu presente e o seu futuro, as suas inquietações e os seus anseios. Se Portugal deseja que o Brasil não o esqueça nem seja infiel à sua tradição e à sua cultura, saiba demonstrar que não se fossilizou, que conseguiu ser tão moderno como na Idade Média ou na Renascença. Por sua vez, o Brasil se quere interessar Portugal não deve limitar-se a exportar os seus escritores especificamente portugueses, por muita gratidão e admiração que nos inspirem, mas também os escritores e artistas tipicamente brasileiros que falam também a nossa língua e não deixam de ser tocados pela asa da mesma saudade, pela nostalgia da velha casa paterna. (FERRO, 1942, p. 12-13).

O discurso de Ferro pressupõe que o presente e o futuro de Portugal estão ancorados na tradição, pois a referência para a modernidade do País é a escala de modernidade que este alcançou na Idade Média e na Renascença. Pode-se compreender essa comparação se se tiver em conta as considerações de Sérgio Buarque de Holanda, em Raízes do Brasil, sobre a fragilidade das relações hierárquicas e a ascensão da burguesia ao poder político desde a Revolução de Avis, elementos que fizeram Portugal se adiantar aos demais Estados europeus, tornando-se uma unidade política e econômica de expressão moderna (HOLANDA, 1986, p. 8). No editorial de Ferro, nota-se também uma valorização dos “escritores e artistas tipicamente brasileiros" (FER- 
RO, 1942, p. 13), que o Brasil deveria dar a conhecer a Portugal, alusão aos modernistas, muitos dos quais colaboraram na revista Atlântico.

Após o editorial de Ferro, há um texto de Fontes, intitulado "Unidade espiritual", em que o autor enfatiza aspectos de dependência e acolhimento entre as duas nações, como a vinda da Corte Portuguesa para o Rio em 1808 e o engrandecimento político e cultural do Brasil que esse fato promoveu. Fontes ecoa a posição de Ferro ao enfatizar as diferenciações que a Língua Portuguesa sofreu no Brasil, como expressão de autonomia, mas também dos laços históricos e culturais que unem os dois povos:

O idioma, que nos liga indissoluvelmente à raça fonte, terá sofrido diferenciações, mas sua estrutura permanece intacta. O vocabulário opulentou-se. A prosódia sofreu metamorfoses sensíveis. Todas essas circunstâncias explicam o fenômeno permanente das nossas simpatias, que resistiram a tudo. (FONTES, 1942, p. 18).

Em "A Realidade do Acordo Cultural: discurso do Embaixador João Neves da Fontoura", publicado na revista Atlântico, em 1943, esse embaixador do Brasil em Portugal entende o Acordo Cultural e a criação da revista Atlântico como instrumentos para aprofundar os laços oceânicos entre Brasil, Portugal e suas, então, colônias africanas. Menciona a criação de uma seção portuguesa e de uma seção brasileira, respectivamente no DIP e no SPN e considera que o Idealismo Atlântico alcançou uma de suas formas concretas com a atuação de António Ferro. Reconhece em José Osório de Oliveira, secretário de redação da Atlântico, um profundo conhecedor da literatura brasileira, o que contribuía para fortalecer os laços culturais de que a revista seria a expressão. Lembra também o sonho de aproximação luso-brasileira de João de Barros (1881-1960) e Paulo Barreto, o João do Rio, (1881-1921), aludindo assim à criação da revista Atlântida, dirigida pelos dois escritores, Barros em Lisboa e Barreto no Rio, que incluía colaboração de escritores lusófonos da geração de 1910-1920 e circulou de 1915 a 1920. 


\section{Peregrinação, literatura de turismo e turismo literário}

O crítico Fernando Cristóvão (2002) delimita o período em que a Literatura de Viagens desperta interesse no público entre fins do século XV, quando se iniciam as Grandes Navegações Ibéricas e se desenvolvem os recursos de imprensa e editoração, e meados do século XIX, quando o mundo já está todo mapeado e se desenvolvem o navio a vapor e o trem. A viagem podia despertar deslumbramento ou temor no viajante, que se via motivado a registrá-la em relatos e imagens. O interesse do leitor advinha da dificuldade do deslocamento, da novidade encontrada e do raro testemunho. Cristóvão propõe uma tipologia da viagem tradicional em cinco categorias: viagem de peregrinação; de comércio; de expansão religiosa, política ou da fé; de erudição, e as viagens imaginárias. As viagens de peregrinação são assim definidas: "Há em todas elas o desejo de se captar um poder ou energia sobrenatural (...), e a vontade de se entrar em comunhão com o Divino, através de uma experiência concreta." (CRISTÓVÃO, 2002, p. 38).

Se na Literatura de Viagens é o encontro com o distante, o diferente e o raro que irão dar origem ao relato, na Literatura de Turismo é a obra literária e seu autor que motivarão o turismo. Em Estudos sobre literatura e turismo, Silvia Quinteiro e Rita Baleiro (2017) assim definem a literatura de turismo e o turismo literário:

(...) a literatura de turismo designa os textos literários que têm o condão de motivar leitores a transformar-se em "turistas de facto", e a realizar viagens para além daquelas que os livros lhes proporcionam, de modo a sentirem-se mais próximos dos livros, dos autores e das personagens. Ou seja, estes textos conseguem promover o turismo literário: um nicho do turismo cultural que tem a especificidade de implicar a deslocação a lugares, de algum modo, relacionados com a literatura. (QUINTEIRO e BALEIRO, 2017, p. 23). 
Para Quinteiro e Baleiro (2017), a obra pode ser incluída no âmbito da literatura de turismo e motivar o turismo literário, se ela contiver referências à prática do turismo e/ou representações do espaço que adquirem o valor de atrações turísticas e/ou reflexões sobre a prática do turismo. Se a obra incluir um ou mais desses fatores, poderá levar os leitores a realizar viagens a fim de se sentirem mais próximos dos seus autores, de suas personagens ou dos cenários representados. $\mathrm{O}$ turismo literário é "um tipo de turismo que consiste na prática de visitar lugares associados a escritores e aos seus textos." (QUINTEIRO e BALEIRO, 2017, p. 36).

Quinteiro e Baleiro (2017) definem os conceitos de espaço, lugar, marcador e itinerário no âmbito dos estudos em Literatura e Turismo. O lugar é uma fração nomeada e ressignificada do espaço. $\mathrm{O}$ que está na base da criação de lugares literários é o conhecimento do texto literário e do seu autor. A referência literária que o leitor "arrasta" para o segmento do espaço geográfico demarcando-o como "lugar literário" é o "marcador": "Em suma, podemos dizer que o lugar literário é uma fração de espaço na qual o turista-leitor reconhece o marcador literário." (QUINTEIRO e BALEIRO, 2017, p. 54). Já o itinerário, para a literatura de turismo, pode ser definido como a descrição de uma relação de lugares literários de interesse a visitar.

Pode-se dizer que os poemas "O vôo sobre as igrejas", de Drummond, e "Poesia de Ouro Preto", de Henriqueta Lisboa, além da crônica "Semana Santa em Ouro Preto", de Cecília Meireles, descrevem itinerários por Ouro Preto, demarcando espaços como lugares de memória coletiva, que se tornam afetivos para os respectivos eu-líricos e para a cronista. Esses textos podem despertar o interesse pela viagem no leitor, a fim de arrastar para o espaço geográfico os marcadores literários e encontrar os lugares neles descritos ou evocar relações com o autor ou com suas criações poéticas. O leitor, transformado em turista, estaria em busca de uma experiência única, autêntica, próxima daquela que Walter Benjamin (1987, p. 170) descreve como "aura": "a 
aparição única de uma coisa distante, por mais perto que ela esteja". Mas, experimentar a "aura" de certos lugares literários depende do grau de "devoção" que o leitor sente pela obra e/ou pelo autor e de informações que assimilou sobre eles. Quanto ao grau de conhecimento e de "devoção" do leitor em relação às suas obras e autores favoritos, Quinteiro e Baleiro (2017) tipificam em três as categorias: o turista literário, o viajante literário e o peregrino literário:

(...) o turista literário não procura novos lugares para decifrar, não procura novos caminhos e experiências inéditas, é um consumidor e, como tal, procura no destino escolhido os produtos literários previamente preparados que são colocados à sua disposição, como sejam os itinerários literários com guia, os festivais literários e as visitas guiadas a casas de autores. $\mathrm{O}$ turista literário pode inclusive sê-lo ocasionalmente, ser alguém que escolhendo um destino com outras motivações, em determinado momento da sua viagem opta por uma atividade de turismo literário. (QUINTEIRO e BALEIRO, 2017, p. 97).

Já o viajante literário é um "apreciador e conhecedor da literatura, alguém versado nos clássicos, disposto a percorrer longas distâncias para estar nos lugares onde literatura e geografia física se encontram." (QUINTEIRO e BALEIRO, 2017, p. 98). Por fim, o peregrino literário é definido como uma variante do viajante literário, que é capaz de percorrer longas distâncias para experienciar

(...) uma comunhão com o autor que admira, (...) ver o que ele viu, sentir o que ele sentiu, estar onde viveu, onde escreveu, onde morreu, onde foi sepultado, sentar-se onde o autor se sentou, observar e tocar os seus objetos. (...) Por essa razão esses lugares são frequentemente experienciados como santuários e os objetos como relíquias. (QUINTEIRO e BALEIRO, 2017, p. 98-99).

A partir dos conceitos de peregrinação, relativo à Literatura de Viagens, de turista, viajante e peregrino literários, relativos ao turismo 
literário, objetivar-se-á identificar os itinerários expressos nos textos que aqui serão analisados e seus possíveis leitores ideais.

\section{Mário de Andrade e o Aleijadinho}

Em 1919, Mário de Andrade viaja a Ouro Preto com o objetivo de buscar referências de uma origem identitária brasileira no Barroco mineiro. Em 1924, retorna às cidades históricas de Minas, acompanhado de um grupo de modernistas paulistas, composto, entre outros, por Oswald de Andrade e Tarsila do Amaral, além do poeta franco-suíço Blaise Cendrars. O grupo encanta-se com as cidades, mas lamenta o abandono do patrimônio arquitetônico e de artes sacras. A defesa da preservação desses bens pelos modernistas contribui para que, em 1933, Getúlio Vargas reconhecesse Ouro Preto como Monumento Nacional. Em 1937, Vargas cria a Secretaria do Patrimônio Histórico e Artístico Nacional (SPHAN), atual IPHAN, e seu diretor, Rodrigo Mello Franco de Andrade, intelectual ligado aos modernistas, encomenda a Manuel Bandeira o Guia de Ouro Preto, cuja primeira edição é de 1938, ano em que a cidade é tombada como Patrimônio Nacional. Para proteger os monumentos históricos e estimular o turismo em Ouro Preto, o Estado Novo cria uma comissão, composta pelo urbanista Lúcio Costa e o arquiteto Oscar Niemeyer, a fim de construir o Grande Hotel, concluído em 1940.

Ainda em 1938, o SPHAN inicia o registro fotográfico de manifestações de cultura popular e promove o tombamento como Patrimônio Nacional de diversos outros conjuntos arquitetônicos pelo Brasil, tais como Diamantina, Serro, Mariana, São João Del Rei e Tiradentes, em Minas Gerais. Com o intuito de dar expressão a sentimentos identitários, o Estado Novo empenha-se para erigir três símbolos de brasilidade, a partir de ideais românticos: Tiradentes, como herói libertário; o mulato, disforme e vencedor das adversidades, Aleijadinho, à maneira de Quasímodo; o poeta Gonzaga e sua musa, à maneira de 
Romeu e Julieta, cujos amores foram sufocados pelos ideais inconfidentes. Para dar materialidade a essa história amorosa, os restos mortais do casal de "pastores" são transladados para o Museu da Inconfidência de Ouro Preto, antiga Casa de Câmara e Cadeia de Vila Rica, em 1942, juntamente com os restos mortais de outros inconfidentes.

O artigo "O gênio e a obra de Aleijadinho", que Mário de Andrade publica no primeiro número da Atlântico, em 1942, insere-se no contexto de tombamento de Ouro Preto (1938), incentivo ao turismo com o Guia de Ouro Preto (1938), construção do Grande Hotel (1940) e do Museu da Inconfidência (1942). Esse artigo foi extraído do ensaio "O Aleijadinho", de 1928, publicado em Aspectos das artes plásticas no Brasil. No ensaio, Andrade não se restringiu a tratar do artista mineiro, menciona poetas, músicos e outros artistas plásticos, que viveram em Minas durante o período colonial. Ao editar o texto para a Atlântico, Andrade incluiu duas fotografias: a fachada da Igreja de São Francisco de Assis, em Ouro Preto, e a estátua do Profeta Jonas, em Congonhas.

Sobre as paredes curvilíneas projetadas por Aleijadinho para as igrejas franciscanas de Ouro Preto e de São João Del Rei, Andrade ressalta aspectos de brasilidade, pois se distinguem "por uma tal ou qual denguice, por uma graça mais sensual e encantadora, por uma 'delicadeza' tão suave, eminentemente brasileiras.” (ANDRADE, 1942, p. 43). Inspirando-se, possivelmente, nos Traços biográficos de Aleijadinho, biografia escrita por Bretas em 1858, Mário de Andrade divide a obra do artista em duas fases, que podem ser exemplificadas com as duas ilustrações, supracitadas, incluídas na edição da Atlântico. O marco divisório entre as duas fases é a doença:

A fase sã de Ouro Preto e São João d'El-Rei se caracteriza pela serenidade equilibrada, e pela clareza magistral. Na fase de Congonhas do enfermo, desaparece aquele sentimento renascente da fase sã, surge um sentimento muito mais gótico e expressionista. A deformação na fase sã é de caracter plástico. Na fase doente é de caracter expressivo. (ANDRADE, 1942, p. 46). 
Andrade, entretanto, considera que nem tudo é bom no Aleijadinho, chegando a colocar em dúvida a autoria de certas obras:

Si na pedra dos profetas se observa apenas uma tal ou qual irregularidade, uma certa hesitação em criar, muito desconfortável, os Passos contêm figuras positivamente deploráveis, que a gente chega a duvidar sejam do Aleijadinho, serão?... Na subida ao Calvário, o Cristo é detestável, e outros horrores se vêem, principalmente na flagelação e na coroação de espinhos. (ANDRADE, 1942, p. 49).

Ao mostrar a deformação de algumas figuras de Aleijadinho, produzidas na idade madura, como sintoma da doença e sob a influência de estilos europeus, Andrade ressalta a síntese entre universalidade e expressões particulares do artista, o que resulta em um "abrasileiramento" de sua arte. Acentua também a condição de artista mulato:

Mas abrasileirando a coisa lusa, lhe dando graça, delicadeza e dengue na arquitectura, por outro lado, mestiço, ele vagava no mundo. Ele reinventava o mundo. (...) É um mestiço, mais que um nacional. Só é brasileiro porque, meu Deus! Aconteceu no Brasil. E só é o Aleijadinho na riqueza itinerante das suas idiosincrasias. E nisto em principal é que ele profetizava americanamente o Brasil... (ANDRADE, 1942, p. 51).

No artigo de 1928, Mário de Andrade considera três outros aspectos em Aleijadinho, excluídos no texto de 1942. O primeiro deles diz respeito ao reconhecimento do artista em sua época. Andrade cita o Livro de registros de fatos notáveis da cidade de Mariana, escrito pelo vereador José Joaquim da Silva, em 1790, em que se menciona Aleijadinho como artista celebrado e caprichoso em seu tempo. Ocorre, no entanto, que essa fonte está desaparecida, quem a menciona é Bretas, que teria se baseado nesse livro e em depoimentos para escrever os Traços biográficos em 1858, 44 anos após a morte do artista. Andrade acrescenta que, embora fossem contemporâneos, não exis- 
tem referências a Aleijadinho na correspondência entre os poetas mineiros e nem mesmo nas Cartas chilenas, atribuídas a Gonzaga: “As 'Cartas Chilenas', apareceram relatando a vida vila-riquense, quando as S. Francisco e N. S. do Carmo já estavam desde muito acabadas. Mas as 'Cartas' não se referem ao Aleijadinho." (ANDRADE, 1984, p. 22). Esse artista também não é mencionado nos documentos relativos à construção da igreja de São Francisco, de São João Del Rei, ao que Mário de Andrade conclui que "talvez Antônio Francisco fosse mesmo desprezado por causa da dor..." (ANDRADE, 1984, p. 22).

O segundo aspecto considerado por Andrade no texto de 1928, ausente no de 1942, diz respeito ao epíteto "primitivo", associado ao artista. Para Andrade, Aleijadinho deu expressão artística pessoal à sua condição de isolamento na colônia, ao seu sofrimento e às influências artísticas recebidas, seria assim símbolo de brasilidade mestiça e sofrida:

Si tal Cristo do Aleijadinho é disforme, um soldado romano é horrível com o seu narigão quase que plasticamente insuportável, si ainda a estátua do São Jorge tem uma carantonha espantada perfeitamente boba, ou si as cúpulas das torres da São Francisco de São João d'El-Rei, são bolotas de mau parecer: é que o Aleijadinho é um "primitivo"... Assim a gente evita de reconhecer o mais legítimo e até mais indispensável direito dos gênios, o direito de errar, o direito de fazer também obras feias e dispensáveis. (ANDRADE, 1984, p. 23).

Por fim, Andrade revela que, além de Bretas, serviu-se de relatos de viajantes estrangeiros do século XIX, entre os quais Richard Francis Burton, que viajou por Minas Gerais em 1867, quando Bretas já havia publicado os Traços biográficos. Burton ficou horrorizado com os Passos de Congonhas, que considerou caricaturais, mas "reconhece que, embora grotescas e vis, essas esculturas serviam para 'fixar firmemente os assuntos no espírito da gente do povo." (ANDRADE, 
1984, p. 26). No diálogo com Burton, Andrade ressalta o didatismo da obra de Aleijadinho ao transmitir a história sacra para o povo simples de sua época, tal como o fizeram muitos artistas medievais europeus.

A posição assumida por Mário de Andrade a respeito da brasilidade de Aleijadinho, da qualidade estética e didática de sua obra e de sua existência como artista individual não é consenso entre críticos e historiadores da Arte. Em edição posterior do texto "O Aleijadinho", Andrade acrescenta uma longa nota de rodapé polemizando com Feu de Carvalho, que, em 1934, havia questionado a autoria e a qualidade de obras atribuídas a Aleijadinho.

Recentemente, outras vozes questionam a existência de um artista individual que se chamou Antônio Francisco Lisboa. Ou, ao menos, que ele seria autor de todas as obras que lhe são atribuídas, que poderiam ter sido produzidas em oficinas onde trabalhavam vários artesãos sob a orientação de um mestre. Essa é a posição de Dalton Sala, que se apoia no fato de não haver menção na correspondência entre os poetas mineiros, especialmente entre Cláudio Manuel e Gonzaga, da existência de Aleijadinho. Em entrevista a Rattner (1996), Sala diz que a figura de Aleijadinho promove a coincidência de um processo de autonomia cultural e autonomia política, esta personificada em Tiradentes, durante o Estado Novo.

Em texto para o site do Projeto Minas Mundo, Luiz Armando Bagolin ao tecer considerações sobre a biografia de Aleijadinho, escrita no século XIX, por Bretas, baseada em referências do Livro de registros de fatos notáveis da cidade de Mariana, desconhecido atualmente, diz que a figura do artista expressa um conjunto de representações, que não tem necessariamente origem em um único artista.

O texto de Mário de Andrade, da Atlântico, discute características estéticas das obras atribuídas a Aleijadinho e situa-as nas cidades históricas de Minas Gerais. Nesse sentido, poderá dialogar com os poemas de Drummond e de Henriqueta Lisboa e com a crônica de 
Cecília Meireles, a serem analisados a seguir, contribuindo para dar materialidade aos roteiros turísticos literários possíveis de serem neles reconhecidos.

\section{Carlos Drummond de Andrade: interdição da transcendência e sublimação artística}

Carlos Drummond de Andrade publica, no primeiro número da revista Atlântico, de 1942, o poema "O vôo sobre as igrejas", que compõe, originariamente, o livro Brejo das Almas, de 1934. Acompanha o poema uma ilustração, sem crédito de autoria, que mostra uma procissão ascendendo na direção de uma igreja, cuja fachada está metade encoberta pela imagem de um anjo segurando uma coroa de louro. A coroa circunda a cruz sobre o centro do teto do edifício, e está posicionada ao lado do campanário.

No poema de Drummond, o eu-lírico convida o leitor a seguir o percurso ascendente do cortejo de Sexta-feira da Paixão. Essa procissão está caracterizada por referências a imagens sacras que lhe são características: o "São Jorge com seu ginete", o "deus coberto de chagas", "a virgem cortada de espadas" e os "Passos da Paixão", sendo que "todos eles jazem na solidão" (DRUMMOND, 1942, p. 114). Os devotos e clérigos, seguidos por anjos, sobem ladeiras até a Matriz de Antônio Dias, ou Matriz de Nossa Senhora da Conceição. O destino é encontrar o túmulo de Aleijadinho: "onde repousa, pó sem esperança, pó sem lembrança, o Aleijadinho.” (DRUMMOND, 1942, p. 113). O crítico Vagner Camilo (2000, p. 51-52) considera que em "O vôo sobre as igrejas", Drummond revela a "visão de um mundo sem transcendência, de total imanência para aqueles que um dia gritaram 'sim! ao eterno"'.

Nesse poema, predominam os versos livres, cujo ritmo, por vezes, sugere o trajeto ascensional dos devotos: "Vamos subindo, vamos deixando a terra lá em baixo, / (...) / empunham coroas, entoam cantos, 
desenham ornatos no azul autêntico." (DRUMMOND, 1942, p. 114). A procissão se faz em um "dia claro", em que "já não há fantasmas". Os serafins e querubins que acompanham os religiosos são carnalizados, pois são "de róseas faces, de nádegas róseas e rechonchudas" (DRUMMOND, 1942, p. 114). Provável alusão aos anjos pintados no teto da Matriz de Antônio Dias, e atribuídos a Aleijadinho. A percepção sinestésica do eu-lírico mostra-se também ao se referir à presença de "cores e cheiros do presente (que) são tão fortes e tão urgentes" (DRUMMOND, 1942, p. 114). Esse conjunto de elementos reforça a hipótese de que a transcendência está interditada e os devotos permanecem presos à imanência do tempo presente, o que já está sugerido no convite à procissão para encontrar a campa do artista.

No percurso ascensional, os anjos carnalizados "entoam cantos, desenham ornatos no azul autêntico" (DRUMMOND, 1942, p. 114). O eu-lírico, assim como os devotos, os clérigos e os “anjos”, elevam-se da terra, o que se evidencia na $1^{\text {a }}$ pessoa do plural que inclui a todos: "Vamos subindo, vamos deixando a terra lá em baixo" (DRUMMOND, 1942, p. 114). Mas o canto que os anjos entoam não é sacro, é em louvor ao artista e a sua vida entre a fé e o pecado. Aleijadinho "lavou na pedra-sabão" (DRUMMOND, 1942, p. 114) os pecados dos devotos ao criar as imagens, de trágica beleza, que, como considera Mário de Andrade, didatizam a fé. Na estrofe em que o eu-lírico dá voz ao canto dos anjos, passa-se do verso livre à forma fixa e musical da redondilha maior, o que poderá mimetizar o apuro formal da obra do artista: "Esse mulato de gênio/ lavou na pedra-sabão/ todos os nossos pecados,/ as nossas luxúrias todas,/ e esse tropel de desejos, / essa ânsia de ir para o céu/ e de pecar mais na terra; (...)" (DRUMMOND, 1942, p. 114).

A procissão em que os anjos entoam esse canto afasta-se, em trajeto ascensional, das "devotas de preto que batem joelho", do "sacristão que limpa os altares" e dos mortos "nas catacumbas e sacristias" (DRUMMOND, 1942, p. 114). Como se aqueles que permanecem 
presos à rigidez de seus ritos religiosos, aos seus sofrimentos e aos seus mortos não pudessem se elevar além de suas vivências temporais. Em contraste, o canto dos "anjos" indicaria que a fruição das formas sublimatórias da arte poderia desprender os devotos para além de seus hábitos.

A interdição da transcendência religiosa é reforçada pelas crianças vestidas de anjos, que entoam cantos em que palavras de sentido sacro como "céu", além de "deus" e "virgem”, essas na voz do eu-lírico, são grafadas com iniciais minúsculas. O canto coletivo do coral dos anjos, em estrofe introduzida pela expressão "Era uma vez", sugere que o artista e sua arte se integraram na memória das narrativas orais populares: "Era uma vez um Aleijadinho,/ não tinha dedo, não tinha mão,/ raiva e cinzel, lá isso tinha," (DRUMMOND, 1942, p. 114). Nessa estrofe, o canto dos anjos adota o verso livre, predominante na maior parte do poema, sugerindo a multiplicidade de vozes que falam a respeito da vida de sofrimentos do artista e da obra que deixou em cidades mineiras:

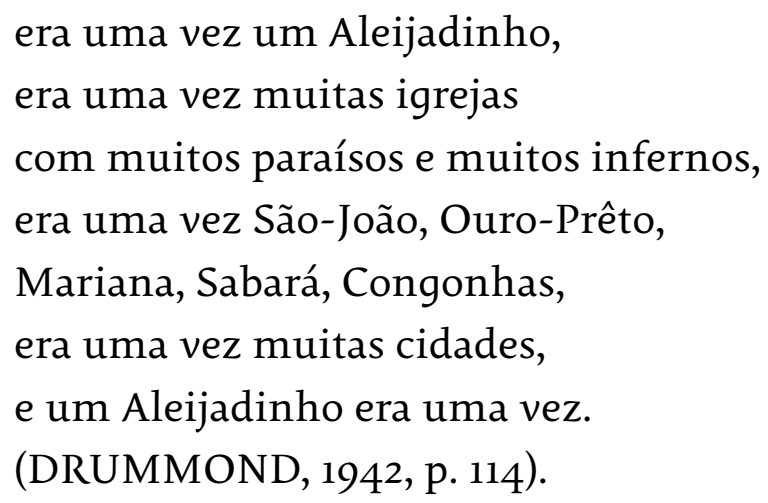

O antropólogo Roberto Da Matta (1997), em A casa e a rua, compreende o Brasil como uma sociedade relacional, tripartida nos planos da "casa” (espaço privado), da "rua” (espaço público) e do "outro mundo" (discurso místico-religioso). O poema "O vôo sobre as igrejas" seria uma expressão dessa sociedade relacional, pois a procissão da Semana Santa, que se integra, em princípio, ao plano do "outro 
mundo", humaniza-se à medida que é a memória de Aleijadinho, referida por sua campa e por suas obras, que se torna objeto de louvor, integrando-se ao espaço público. Ao se tornarem objetos de devoção, memória e obra são também incorporadas ao plano da "casa", como está sugerido no tratamento que o eu-lírico e os devotos dão ao artista. Este não é conhecido pelo nome de batismo ("outro mundo"), Antônio Francisco Lisboa, mas pelo apelido diminutivo de "Aleijadinho" ("casa"), que o marca com a doença que o atingiu na maturidade. Esse apelido ultrapassa o plano da "casa", se íntegra à "rua" e torna-se narrativa popular, expressa na última estrofe do poema. A multiplicidade de vozes da narrativa popular, mimetizada pelos versos livres, faz de uma doença, que teria marcado o artista em uma fase madura da vida, metonímia de toda a sua vida, convertendo-se no epíteto com que ele ficou conhecido. Para Mário de Andrade, as obras de Ouro Preto e São João Del Rei não foram realizadas quando o artista "não tinha dedo, não tinha mão" (DRUMMOND, 1942, p. 114), essa foi uma condição que o afetou em seu trabalho em Congonhas. Mas, na narrativa popular, o epíteto e a doença que ele expressa tornam-se referências atemporais nos planos privado, da vivência sentimental, e público, da memória coletiva.

Em síntese, "O vôo sobre as igrejas" é composto por estrofes e versos irregulares. Por duas vezes, o eu-lírico dá voz ao coral de serafins e querubins. Na primeira vez, esse coral, em redondilhas maiores, louva a memória de Aleijadinho - sua obra e sua vida cheia de contradições. Na estrofe final do poema, em versos livres, os anjos iniciam seu canto por "Era uma vez", expressão que se repete em seis dos dez versos dessa estrofe, sendo que ela encerra o último verso. Se as redondilhas maiores mimetizam a perfeição da obra, os versos livres e a expressão anafórica "Era uma vez" sugerem que a memória do artista integrou-se à narrativa oral popular em sua multiplicidade de vozes. O último verso do poema: "e um Aleijadinho era uma vez" (DRUMMOND, 1942, p. 114), alude à circularidade da voz 
coletiva, que recupera a memória do artista do esquecimento. Assim, a procissão dirige-se até a campa do artista esquecido ("pó sem esperança, pó sem lembrança"), seguida por anjos humanizados, que "fogem conosco" (DRUMMOND, 1942, p. 114), para louvar, não a Paixão de Cristo, mas a memória do artista esquecido e integrá-la à narrativa coletiva.

\section{Itinerário lírico e histórico de Henriqueta Lisboa por Ouro Preto}

Henriqueta Lisboa publica "Poesia de Ouro Preto" no segundo número da revista Atlântico, de 1946, datado de 17 de setembro. No mesmo ano, esse poema fora também publicado no livro Madrinha Lua, mas há referências a ele em cartas trocadas entre Henriqueta Lisboa e Mário de Andrade em 1942 (OLIVEIRA, 2018, p. 26-27). Nas primeiras páginas desse número da Atlântico, de 1946, há uma homenagem a Mário de Andrade, falecido em 25 de fevereiro de 1945, por meio da reprodução fotográfica de seu busto, esculpido por Bruno Giorgi, em 1945.

A crítica Ilca Vieira de Oliveira (2018, p. 34) considera que "Poesia de Ouro Preto" revela "um sujeito que, a partir do presente, vai criando uma imagem do passado com uma linguagem reflexiva e meditativa”. Há, no poema, referências a Marília de Dirceu, a Filipe dos Santos, líder da Revolta de Vila Rica em 1720, a Cláudio Manuel da Costa, a Aleijadinho, a Tiradentes, entre outras personalidades históricas e literárias. Há menção a uma procissão, que pode ser a de Corpus Christi, quando ruas e casas são adornadas. Monumentos e obras de arte são também referidos: o antigo Solar dos Ferrão, onde viveu Maria Doroteia Joaquina de Seixas Brandão, a Marília, com seus tios; a Ponte de António Dias ou Ponte dos Suspiros, a Igreja de Nossa Senhora das Mercês e dos Perdões, a Casa dos Contos, o São Jorge de Aleijadinho, as ruas de pedra-sabão. 
"Poesia de Ouro Preto" está estruturado em 96 versos distribuídos em 12 estrofes irregulares, os versos são em redondilha maior. A irregularidade das estrofes pode sugerir o fluxo de reminiscências do eu-lírico a partir das quais vai compondo seu trajeto nas ruas, também irregulares, de Ouro Preto. Em contraste, a regularidade da redondilha maior pode aludir à relação harmoniosa entre o eu-lírico e a cidade, sendo, por vezes, usada para mimetizar a lentidão do trabalho da memória.

Nas quatro primeiras estrofes, o olhar do eu-lírico se aproxima do de Marília: o itinerário por Ouro Preto se inicia na antiga casa da musa, o Solar dos Ferrão. O eu-lírico refere-se à atitude de reflexiva expectativa ("cismar e cismar"), que a tradição atribui a Marília após o desfecho do noivado com Gonzaga, a prisão e posterior extradição do poeta para Moçambique. Em seguida, descreve a casa: "Ó cidade de Ouro Preto/ boa da gente morar!/ Numa casa com mirantes/ entre malvas e gerânios/ ter os olhos de Marília/ para cismar e cismar!" (LISBOA, 1946, p. 23), situada na parte alta da cidade ("rua de escadinhas"), com grandes janelas, de onde o eu-lírico, em ambiente diurno, poderia "passar (...) o dia / vendo a vida que não anda" (LISBOA, 1946, p. 23) da pacata Ouro Preto.

Em contraste, nas duas estrofes seguintes, a ambientação passa a ser noturna, o que traduz uma interiorização do eu-lírico, ainda identificado a Marília: "E de noite vendo a lua/ como uma camélia opaca/ (...) escutando as serenatas/ de clarinete e violão/ evocar tempos perdidos" (LISBOA, 1946, p. 23). O luar evoca as recordações de família, sugeridas pelo ritmo lento que as redondilhas maiores assumem nos versos: "abrir o baú de folha/ que é lembrança de família,/ baú onde criam mofo/ cartas velhas e retrato/ de algum namorado ingrato." (LISBOA, 1946, p. 23). As serenatas ouvidas trazem à lembrança a Ponte de Antônio Dias, conhecida por Ponte dos Suspiros porque a tradição atribui a ela um lugar de encontros entre Gonzaga e Maria Doroteia, que aparecem por meio da perífrase de os "noivos 
que não casaram": "quando a Ponte dos Suspiros/ - hoje povoada de sapos - / era a ponte dos encontros/ dos noivos que não casaram." (LISBOA, 1946, p. 23).

A ambientação permanece noturna (“desoras”) na $5^{\text {a }}$ estrofe, mas o eu-lírico se descola da identificação com Marília, pois as batidas dos cascos dos cavalos a galope lembram um fato histórico, a Revolta de Vila Rica, ocorrida em 1720, e o enforcamento de seu líder, o comerciante Filipe dos Santos: "aquele cavalo bravo / que deu martírio e deu morte / crua a Filipe dos Santos." (LISBOA, 1946, p.24). Ao amanhecer, o eu-lírico caminha até a Igreja das Mercês e dos Perdões, cujo risco da capela mor é atribuído a Aleijadinho. Embora "ajoelhada no adro", não há reza, permanece "na contemplação feliz / das volutas e dos frisos" (LISBOA, 1946, p. 24), depois retorna para casa com o espírito ("coração de passarinho"), fruindo ("navegando") o prazer do "ar da montanha".

Novamente anoitece, e o eu-lírico refaz o trajeto até a Igreja das Mercês e dos Perdões "para assistir à novena” (LISBOA, 1946, p. 25). No caminho, passa pela Casa dos Contos, que remete a uma personalidade literária e histórica, o poeta inconfidente Cláudio Manuel da Costa. Historicamente, a Casa dos Contos foi construída entre 1782 e 1784 pelo contratador João Rodrigues de Macedo. Depois, entregue como pagamento de dívidas à Coroa Portuguesa, serviu como prisão de Cláudio Manuel, onde ele teria se suicidado, fato aludido nos versos finais dessa estrofe: "onde mora a alma penada / de Cláudio Manuel, coitado!” (LISBOA, 1946, p. 25). Em 1797, a antiga casa residencial passa a abrigar a sede da administração e contabilidade pública da Capitania de Minas Gerais, daí o nome de Casa dos Contos, como referida no poema. Na sequência de seu trajeto, o eu-lírico lembra do Aleijadinho: "Pisar com carinho as ruas/ que o Aleijadinho pisou/ marcando-as com a sua força/ como se essas ruas fossem/ lotes de pedra sabão." (LISBOA, 1946, p. 24-25). Os "lotes de pedra sabão", onde pisou Aleijadinho e pisa o eu-lírico, pode expres- 
sar, por sua porosidade, a relação harmoniosa entre este e a cidade, além da grandeza ("lotes") da obra do artista.

O foco se desloca, na $9^{\text {a }}$ estrofe, para as reminiscências de um cortejo religioso ("quando houver procissão"), quando se pode ver a imagem de São Jorge, esculpida por Aleijadinho, que a tradição atribui ter sido inspirada pelo rosto de Tiradentes: "para ver a carantonha / do alferes que se presume.” (LISBOA, 1946, p. 25). Em seguida, a lembrança torna-se sinestésica, traduzindo-se na descrição de aromas e adornos das "casas nobres" para esperar a passagem da procissão: "E, enquanto das casas nobres/ vem almíscar de alfazema/ por entre colchas de seda/ e franjas pelas sacadas," (LISBOA, 1946, p. 25). Dessa percepção sinestésica passa-se à memória histórica, quando a Casa dos Contos reaparece por meio de uma alusão metonímica aos inconfidentes, que lá se reuniam, quando fora de Macedo, onde alguns deles chegaram a se esconder: "a casa em que se reuniam / em volta da mesa grande / os homens da capa preta." (LISBOA, 1946, p. 2526). Com versos entre parênteses, há menção a um suposto fenômeno do campo do maravilhoso, que integra as crenças retransmitidas em narrativas populares ("há quem diga"), e alimenta o mito de Tiradentes como herói emancipacionista: "(Numa parede - há quem diga -/ existe uma cruz de sangue/ com que jurou Tiradentes,/ uma cruz que se ilumina/ no dia vinte e um de Abril)." (LISBOA, 1946, p. 25-26).

A penúltima estrofe se inicia com o verso que dá título ao poema: “Ó poesia de Ouro Preto!” (LISBOA, 1946, p. 26). Lirismo que vem da percepção da antiguidade de suas ruas ("Em cada beco ver sombras / que já desapareceram"), dos sons ancestrais das igrejas ("Em cada sino ouvir sons, / badaladas de outros tempos."), de suas construções monumentais ("Em cada arranco do solo, / batida de pedra e cal,"), que se integraram à memória coletiva e ao patrimônio nacional ("ver a eternidade em paz.”). E, na última estrofe, são retomados os dois versos iniciais do poema: "Ó cidade de Ouro Preto / boa da gente morar!" (LISBOA, 1946, p. 26). Nessa cidade, em que se fundem afe- 
tos vividos e temporalidade histórica, é também boa para concluir o ciclo da vida: "E esperar a hora da morte / sem nenhum medo nem pena / - quando nada mais espera." (LISBOA, 1946, p. 26).

O poema de Henriqueta Lisboa tece um percurso, ao mesmo tempo lírico, histórico, artístico e literário por Ouro Preto, com a duração aproximada de dois dias. Nele há referências à Igreja das Mercês e dos Perdões, à procissão de Corpus Christi, à novena e ao suposto milagre da cruz que se ilumina, elevando Tiradentes ao plano de mártir ungido. Mas, esses elementos parecem ser menos manifestação de crença religiosa que evocação afetiva da história da cidade e de suas expressões artísticas e culturais. Como no poema "O vôo sobre as igrejas", há também em "Poesia de Ouro Preto" certa circularidade, pois Ouro Preto é cidade "boa da gente morar!" (LISBOA, 1946, p. 23), como também para "esperar a hora da morte" (LISBOA, 1946, p. 26). Se em Drummond a circularidade diz respeito à retransmissão da memória de Aleijadinho, em Lisboa ao ciclo de vida do eu-lírico, sob cujo percurso alude à densidade histórica e artística de Ouro Preto. Na metáfora da porosidade da pedra-sabão, harmoniza-se o abraço afetivo entre o eu e a cidade.

"O vôo sobre as igrejas" e "Poesia de Ouro Preto", publicados, na Atlântico se inserem no contexto de políticas de valorização da cidade e das personalidades a ela ligadas: Tiradentes, Gonzaga e Aleijadinho. E é preciso lembrar que a política de patrimonialização, assumida por Rodrigo Mello Franco de Andrade, transcende a existência do Estado Novo, pois ele permanece à frente do IPHAN até 1967.

\section{Cecília Meireles e o turismo literário e religioso}

O último número da revista Travel in Brazil, de 1942, trouxe uma longa crônica de Cecília Meireles intitulada "Holy-week in Ouro Preto" ("Semana Santa em Ouro Preto"), ilustrada com fotografias de Jean Manzon e de Erich Hess. Cecília a inicia com a informação sobre o tombamento do conjunto arquitetônico de Ouro Preto por ação de 
Vargas, que transformou essa "vila portuguesa", erguida nas montanhas de Minas Gerais, em uma cidade museu e proibiu construções e demolições que a desfigurassem. Cecília diz que isso não impediu a cidade de abrigar turistas em casas de família e menciona a construção do Grande Hotel, em estilo moderno, que tornará a cidade mais acessível. A cronista passa a descrever os encantos de uma viagem por via rodoviária até Ouro Preto e refere-se às duas personalidades ligadas à cidade e à Inconfidência que o Estado Novo contribuiu para valorizar como expressões de brasilidade, Tiradentes e Gonzaga:

Após seguir o caminho sinuoso em torno de desfiladeiros e precipícios, em estradas de perigosa beleza, chega-se a Ouro Preto, cerca de 3.300 pés acima do nível do mar; Ouro Preto, a célebre "Vila Rica", à qual dois fatos importantes da história brasileira são atribuídos: o martírio de Tiradentes, e o amor do poeta Gonzaga, ambos fazendo parte do dramático episódio chamado de "Inconfidência Mineira", o movimento de independência, em 1789. (MEIRELES, 1942, p. 15 - tradução nossa)'.

Meireles menciona a riqueza advinda da prospecção do ouro nos tempos coloniais e os garimpeiros remanescentes. Ao adentrar a cidade, introduz a Semana Santa, a partir de duas celebrações que seriam familiares aos leitores estrangeiros: as de Oberammergau e Sevilha. Menciona ainda a opulência das procissões nos tempos coloniais. quando se extraía o ouro em grande quantidade. Após o esboço histórico, Meireles apresenta minucioso itinerário para os sete dias da Semana Santa em Ouro Preto.

1 "After winding aroung gorges and precipices, on roads of dangerous beauty, one reaches Ouro Preto, nearly 3300 feet above sea levels; Ouro Preto the celebrated 'Vila Rica', to which two important facts of Brazilian history are attributed: the martyrdom of Tiradentes, and the love of the Poet Gonzaga, both forming a part of the dramatic episode called the 'Inconfidência Mineira', the movement for Independence in 1789." (MEIRELES, 1942, p. 15). 
O itinerário se inicia no Domingo de Ramos, quando a poeta chega a Ouro Preto e se depara com tropeiros que levam suas mercadorias para serem comercializadas na cidade em lombos de mulas, o que lembra "as imagens da história sagrada que vimos em nossa infância” (MEIRELES, 1942, p. 16 - tradução nossa)', representativas da entrada de Jesus em Jerusalém. Descreve o centro de Ouro Preto, com a Praça Tiradentes, a Escola de Minas e o Museu da Inconfidência. Da Igreja das Mercês e dos Perdões, a imagem da Virgem Maria sairá para encontrar o filho, esse é o tema da Procissão do Encontro. Chegam muitas famílias e crianças vestidas de anjo. Depois do cortejo do Domingo de Ramos, os fiéis descansam na igreja e os menos fiéis logo se divertem na quermesse, em clubes de dança, salões de bilhar, cinemas e cafés. Informações que associam a cidade, antiga e religiosa, a entretenimentos modernos, que poderão ser atrativos a turistas religiosos ou não em suas várias nuances.

Na segunda-feira, ouve-se, pela manhã, o badalar dos sinos. A poeta relata as visitas que faz a algumas das mais de vinte igrejas de Ouro Preto e descreve seus trabalhos artísticos: Igreja do Carmo, de Santa Ifigênia, das Mercês, de São Francisco de Paula. Aparece a única menção direta a Aleijadinho na crônica: "Cada igreja tem um interesse particular: algumas pelas esculturas de Aleijadinho" (MEIRELES, 1942, p. 21 - tradução nossa)3. Informa que, também na terça-feira, não haverá procissão e sugere ao leitor-turista uma viagem a Mariana.

2 "Palm Sunday, we enter Ouro Preto; this year it happens to be the same day on which Jesus entered Jerusalem, and we see on the roads countless packmules coming from far places, and climbing the abrupt hills, carrying muleteers and merchandise (...) and we recall the images of sacred history which we saw in our childhood." (MEIRELES, 1942, p. 16).

3 "Each church has its own particular interest: some for the sculptures of the 'Aleijadinho'; others for their paintings, these latter for their traditions, and the former for the richness of the carvings." (MEIRELES, 1942, p. 21). 
Na quarta-feira, há a missa noturna na Igreja Paroquial, ao lado da Matriz de Antônio Dias, onde se pode ouvir a Orquestra Sacra de Ouro Preto. Na quinta-feira, não há sinos badalando, apenas o som das matracas, que anunciam o sofrimento de Cristo. À noite, realiza-se o Sermão do Mandato. Os discípulos são representados por doze meninos, que participam da cerimônia do Lava-pés com a presença do bispo de Mariana. Depois, devotos e curiosos podem apreciar a representação da Última Ceia nas igrejas.

Na sexta-feira, celebra-se a "Canção da Paixão", quando se encena o julgamento de Jesus, na forma de um recital. A descida da cruz acontece ao crepúsculo. A Procissão da Paixão passa por toda a cidade e é descrita minuciosamente. No sábado, há a benção do fogo da Páscoa, que ocorre nas igrejas da cidade. Depois, há o cortejo do Judas, que chega até a Praça Tiradentes, quando as crianças se divertem com esse ritual de vingança. No Domingo de Páscoa, há a Procissão da Ressurreição pela manhã. As ruas, as varandas e as janelas das casas são enfeitadas. A procissão passa de igreja em igreja.

As fotografias de Jean Manzon e Erich Hess, que ilustram a crônica, mostram detalhes arquitetônicos da cidade, como a Praça Tiradentes, detalhes das várias procissões, as representações da Última Ceia, do Martírio de Jesus, do cortejo, do Sudário de Santa Verônica e da cerimônia do Lava-pés. Há também fotografias das crianças, vestidas de anjos, que podem materializar os "serafins" e "querubins" referidos no poema de Drummond. Assim Cecília descreve as crianças: “Anjos bebês, nos braços, anjos de um ano, dois anos, ainda vacilantes em suas pernas, anjos roucos de 5 e 6 anos, anjos com caras limpas e com caras sujas, arianos e não arianos, de ambos os sexos, anjos sonolentos, e anjos gripados." (MEIRELES, 1942, p. 17 - tradução nossa)4. Chama

4 "Angel-babies in Arms, angels of 1 year, 2 years, still wobbly on their legs, huskier angels of 5 and 6 years, angels with clean faces and dirthy faces, aryans and nonaryans, of both sexes, sleepy angels, and angels with colds." (MEIRELES, 1942, p. 17). 
a atenção, em pelo menos duas das fotografias, a presença de crianças brancas, quase louras ("arianas"), em primeiro plano. Mas, em consonância com a proposta do Modernismo brasileiro de valorizar a miscigenação racial no Brasil, as fotografias de Manzon e Hess também registram a presença de crianças e adultos pardos e negros, que se misturam com outros de pele branca, durante as celebrações da Semana Santa em Ouro Preto. Isso parece indiciar que os colaboradores gozavam de certa liberdade expressiva, a despeito de a Travel in Brazil ser uma publicação do DIP e o Estado Novo pretender apresentar ao estrangeiro um Brasil “embranquecido” e em vias de modernização.

\section{Considerações finais}

O ensaio de Mário de Andrade tem caráter informativo sobre a obra e a vida de Aleijadinho, podendo contribuir para constituir um arcabouço de conhecimentos do viajante literário em Ouro Preto. Nos textos de Drummond, Henriqueta Lisboa e Cecília Meireles é possível reconhecer, em ordem crescente de materialidade, itinerários líricos que se compõem de sequências de "lugares literários" que o leitor poderá "arrastar" para o espaço geográfico, tornando-os "marcadores literários" durante uma viagem à cidade. Os "marcadores" são lugares vividos afetivamente durante a leitura e que se tornaram alvos de visitação, como forma de o leitor, convertido em turista, viajante ou peregrino literário, em suas várias nuances, se aproximar do texto e de seu autor.

A crônica de Cecília Meireles é texto inédito publicado em uma revista destinada a divulgar turisticamente o Brasil nos Estados Unidos. Tal como o Guia de Ouro Preto, de Manuel Bandeira, foi concebido como literatura de turismo, avant la lettre. Em "Semana Santa em Ouro Preto", Cecília compõe um itinerário turístico-literário de sete dias, com um grau de materialidade que o aproxima de um guia informativo. Há nesse texto uma intenção de orientar o turista ou o 
viajante literário sobre o que ver em Ouro Preto durante a Semana Santa, a partir de uma sequência de atividades religiosas, que a cronista acompanha e descreve sentimentalmente. A crônica também traz informações sobre hospedagem, paisagem regional, acontecimentos históricos, monumentos arquitetônicos, ruas, praças e igrejas, arte sacra e manifestações de cultura popular. A qualidade estética do material fotográfico, de autoria de Manzon e Hess, contribui para a divulgação turística da cidade. Pode ser considerado literatura de turismo por expressar uma visão singular de uma escritora reconhecida e conter aspectos informativos capazes de despertar o interesse do leitor pela viagem, tornando-se turista ou viajante literário. Sendo destinado ao leitor de língua inglesa, talvez pouco afetasse um peregrino literário, pois trata-se de um público de possíveis leitores entre os quais Cecília Meireles fosse pouco conhecida para inspirar certa “devoção" literária. O texto poderia, no entanto, inspirar o turista religioso, a viagem de peregrinação, um dos tipos mais ancestrais de viagem, segundo Cristóvão (2002).

Diferentemente do Guia de Ouro Preto, de Manuel Bandeira, e de "Semana Santa em Ouro Preto", planejados e escritos como literatura de turismo, avant la lettre; os poemas de Drummond e de Henriqueta Lisboa não são roteiros turísticos, mas podem nortear o leitor em um passeio pela cidade, a partir da experiência afetiva com a leitura desses poemas. Publicados na revista binacional Atlântico, podem ter contribuído para divulgar nacional e internacionalmente Ouro Preto, como patrimônio histórico e artístico.

No poema "O vôo sobre as igrejas", de Drummond, o eu-lírico demarca "lugares literários", como a Matriz de Antônio Dias, para onde a procissão se dirige, e onde se situa a campa de Aleijadinho. Faz referências ao São Jorge e aos Passos da Paixão. Nesse poema, o canto dos anjos menciona outras cidades em que há obras de Aleijadinho: São João Del Rei, Ouro Preto, Sabará e Congonhas. A partir de referências materiais a igrejas, esculturas sacras e outras obras de 
Aleijadinho, o turista literário poderá compor seu itinerário afetivo pelas cidades históricas de Minas Gerais.

Em "Poesia de Ouro Preto", o itinerário literário de Henriqueta Lisboa adquire um grau maior de precisão e materialidade, dada a sequência de "lugares literários" referidos e alusões a acontecimentos históricos, que o turista literário poderá “arrastar" para o espaço geográfico e constituí-los em uma sequência de "marcadores" literários, ou seja, em um itinerário turístico literário. São eles: o casarão de Marília no bairro de Antônio Dias, a Ponte dos Suspiros, as "calçadas", metonímia das ruas de pedra, de Ouro Preto, onde Filipe dos Santos foi martirizado, a Igreja das Mercês e dos Perdões, a Casa dos Contos, a Procissão de Corpus Christi com as casas adornadas, a escultura do São Jorge, "cada beco", "cada sino", "batida de pedra e cal", metonímias, respectivamente, das ruas e cantos estreitos, das igrejas e seus campanários, dos monumentos arquitetônicos.

Drummond e Henriqueta Lisboa fazem referências a procissões religiosas e obras sacras, mas apresentam Ouro Preto a partir de uma visão secular. Em Drummond, os "anjos", durante a procissão da Paixão, cantam a memória de Aleijadinho e suas contradições. Em Henriqueta Lisboa, o eu-lírico contempla os pormenores da Igreja das Mercês e dos Perdões. Durante a procissão, há a sinestesia de aromas, texturas e cores. Assim, esse eu-lírico se aproxima ao do poema de Drummond, cuja percepção também é marcada pela experiência dos sentidos ("dia claro", "cores e cheiros" fortes do "presente”).

Se Drummond seculariza a procissão, deslocando o louvor para Aleijadinho; se Lisboa se entretém com a contemplação estética e sinestésica, centram-se, assim, na exaltação da arte e da paz de espírito que ela proporciona; Meireles não se distancia da experiência religiosa e pode tanto levar o turista-literário a encantar-se com aspectos de manifestações de cultura popular, a partir de um olhar secular e curioso para a religiosidade, quanto pode levá-lo a se inserir no universo de devoção religiosa e da arte sacra que lhe corresponde. 
RECEBIDO: 25/03/2021 APROVADO: 12/08/2021

\section{REFERÊNCIAS}

ANDRADE, Mário. O gênio e a obra de Aleijadinho, Atlântico: revista luso-brasileira, Lisboa-Rio de Janeiro: Edição do SPN e do DIP, n. 1, p. 40-51, Primavera de 1942. Disponível em: http://hemerotecadigital.cmlisboa.pt/Periodicos/Atlantico_RevistaLusoBrasileira/Atlantico.htm. Acesso em: 15/10/2020.

ANDRADE, Mário. Aspectos das Artes Plásticas no Brasil. $3^{\mathrm{a}}$. ed. Belo Horizonte: Itatiaia, 1984.

BAGOLIN, Luiz Armando. "O Aleijadinho" e sua recepção histórica e crítica, Projeto Minas Mundo. Disponível em: https://projetominasmundo. com.br/pessoas/o-aleijadinho-e-sua-recepcao-historica-e-critica/. Acesso em: $23 / 02 / 2021$.

BANDEIRA, Manuel. Guia de Ouro Preto. São Paulo: Global, 2015.

BENJAMIN, Walter. A Obra de arte na era de sua reprodutibilidade técnica, Obras Escolhidas: - magia e técnica, arte e política. Tradução de Sergio Paulo Rouanet. São Paulo: Brasiliense, 1987.

CAMILO, Vagner. Uma poética da indecisão: Brejo das Almas, Novos Estudos CEBRAP, n. 57, p. 37-58, julho de 2000.

CRISTÓVÃO, Fernando. Para uma teoria de literatura de viagens, Condicionantes culturais da literatura de viagens. Coimbra: Almedina, 2002.

DA MATTA, Roberto. A Casa e a Rua. $5^{\mathrm{a}}$. ed. Rio de Janeiro: Rocco, 1997.

DRUMMOND DE ANDRADE, Carlos. O vôo sobre as igrejas, Atlântico: revista luso-brasileira, Lisboa-Rio de Janeiro: Edição do SPN e do DIP, n. 1, p. 113-114, Primavera de 1942. Disponível em: http://hemerotecadigital. cm-lisboa.pt/Periodicos/Atlantico_RevistaLusoBrasileira/Atlantico.htm. Acesso em: 15/10/2020.

FERRO, António. Algumas palavras, Atlântico: revista luso-brasileira, Lisboa-Rio de Janeiro: Edição do SPN e do DIP, n. 1, p. 11-13, Primavera de 1942. Disponível em: http://hemerotecadigital.cm-lisboa.pt/ Periodicos/Atlantico_RevistaLusoBrasileira/Atlantico.htm. Acesso em: $15 / 10 / 2020$. 
FONTES, Lourival. Unidade espiritual, Atlântico: revista luso-brasileira, Lisboa-Rio de Janeiro: Edição do SPN e do DIP, n. 1, p. 17-19, Primavera de 1942. Disponível em: http://hemerotecadigital.cm-lisboa.pt/Periodicos/ Atlantico_RevistaLusoBrasileira/Atlantico.htm. Acesso em: 15/10/2020.

FONTOURA, João Neves da. A realidade do acordo cultural, Atlântico: revista luso-brasileira, Lisboa-Rio de Janeiro: Edição do SPN e do DIP, n. 4, p. 11-14, 1943. Disponível em: http://hemerotecadigital.cm-lisboa.pt/ Periodicos/Atlantico_RevistaLusoBrasileira/Atlantico.htm. Acesso em: $15 / 10 / 2020$.

HOLANDA, Sérgio Buarque de. Raízes do Brasil. Rio de Janeiro: José Olympio, 1986.

LISBOA, Henriqueta. Poesia de Ouro Preto, Atlântico: revista lusobrasileira, Lisboa-Rio de Janeiro: Edição do SNI e DNI, n. 2, p. 23-26, 1946. Disponível em: http://hemerotecadigital.cm-lisboa.pt/Periodicos/ Atlantico_RevistaLusoBrasileira/Atlantico.htm. Acesso em: 15/10/2020.

MEIRELES, Cecília. Holy-week in Ouro Preto, Travel in Brazil, Rio de Janeiro: DIP, v. 2, n. 4, p. 14-32, 1942.

OLIVEIRA, Ilca Vieira de. Henriqueta Lisboa \& Mário de Andrade: um diálogo sobre os “Três Poemas da Terra”, Revista Araticum. Programa de Pós-Graduação em Letras/Estudos Literários da Unimontes, v. 17, n. 1, p. 16-37, 2018.

QUINTEIRO, Sílvia; BALEIRO, Rita. Estudos em literatura e turismo. Lisboa: Universidade de Lisboa, 2017.

RATTNER, Jair. Pesquisador diz que Aleijadinho é mito, Folha de S. Paulo, Ilustrada, 16 de março de 1996. Disponível em: https://www1.folha.uol. com.br/fsp/1996/3/16/ilustrada/19.html. Acessado em 22/02/2021.

RIBEIRO, Carla. Um intelectual orgânico no Estado Novo de Salazar: as ideias e os projetos de luso-brasilidade de António Ferro, Intellèctus. Rio de Janeiro: UERJ, ano XVI, n. 2, p. 45-67, 2017a. Disponível em: https://www.e-publicacoes.uerj.br/index.php/intellectus. Acessado em: $15 / 10 / 2020$.

RIBEIRO, Carla. A educação estética da nação e a "Campanha do Bom Gosto" de António Ferro (1940-1949). Estudos Ibero-Americanos, Porto Alegre: PUC-RS, v. 43, n. 2, p. 289-302, maio-agosto de 2017b. Disponível em: https://revistaseletronicas.pucrs.br/index.php/iberoamericana/issue/ view/1121. Acesso em 15/10/2020. 


\section{Minicurrículo}

Luís Antônio Contatori Romano é doutor em Teoria e História Literária pela Unicamp, com pós-doutorado em Literatura Brasileira pelo IEB-USP. É autor dos livros A Passagem de Sartre e Simone de Beauvoir pelo Brasil em 1960 (2002), A Poeta-Viajante: Uma Teoria Poética da Viagem Contemporânea nas Crônicas de Cecília Meireles (2014) e Cecília Meireles e a Travel in Brazil (1941-1942) (2019). É professor de Estudos Literários na Universidade Federal do Sul e Sudeste do Pará (Unifesspa) e bolsista Produtividade do CNPq. 